\title{
Integração geofísico-geológica da região entre Tunas do Paraná e Adrianópolis, Vale do Ribeira, Paraná
}

Guilherme Fedalto ${ }^{1}$, Leonardo Fadel Cury², Francisco José Fonseca Ferreira ${ }^{2}$. ${ }^{1}$ Programa de Pós-Graduação em Geologia da Universidade Federal do Paraná, ${ }^{2}$ Departamento de Geologia da Universidade Federal do Paraná

Copyright 2016, SBGf - Sociedade Brasileira de Geofísica

Este texto foi preparado para a apresentação no VII Simpósio Brasileiro de Geofísica, Ouro Preto, 25 a 27 de outubro de 2016. Seu conteúdo foi revisado pelo Comitê Técnico do VII SimBGf, mas não necessariamente representa a opinião da SBGf ou de seus associados. É proibida a reprodução total ou parcial deste material para propósitos comerciais sem prévia autorização da SBGt.

\begin{abstract}
The aim of this paper is to discuss the integration of geological and geophysical data in the region between Tunas do Paraná e Adrianópolis, Ribeira Valley, State of Paraná. To generate the geological database, a Geographic Information System (GIS) was developed based on geological map in 1:25,000 scale, extracted from the 90's geological surveys. The area involves paleoproterozoic Tigre's Nuclei, mesoproterozoic metassedimentary and metavulcanossedimentary rocks from Perau and Votuverava formations, neoproterozoic Varginha Magmatic Suit and mesozoic basic dykes. The mineralization is hosted in calc-silicate rocks from Perau Formation, which was composed by $\mathrm{Pb}-\mathrm{Zn}-\mathrm{Cu}$ sulfides massive horizons. The airborne gamma-ray spectrometric and magnetic data were acquired by CPRM. The gamma spectrometry, utilizing $\mathrm{K}$, eTh, eU and ternary maps, allowed making a litho-geophysical map. The magnetometry provided a magnetic-structural map, where it was possible to identify shear zones, minor expressive faults and metabasic rocks.
\end{abstract}

\section{Introdução}

A presente pesquisa é uma síntese do Trabalho de Conclusão de Curso apresentado por Fedalto (2015). A integração de dados geológicos e aerogeofísicos teve como objetivo a concepção de um mapa litogeofísico e a interpretação de anomalias magnéticas, com base em dados gamaespectrométricos e magnetométricos, respectivamente. Os dados geológicos foram resgatados de Daitx (1996) e integrados aos dados geofísicos em ambiente de Sistema de Informações Geográficas (SIG). Os dados aerogeofísicos do Projeto Paraná-Santa Catarina foram cedidos à Universidade Federal do Paraná pelo Serviço Geológico do Brasil (CPRM, 2011).

A área de estudo está inserida entre os municípios de Tunas do Paraná e Adrianópolis, Estado do Paraná (Fig. 1). $O$ acesso a partir de Curitiba é feito pela BR-476 até o município de Tunas do Paraná, percorrendo 73 quilômetros.

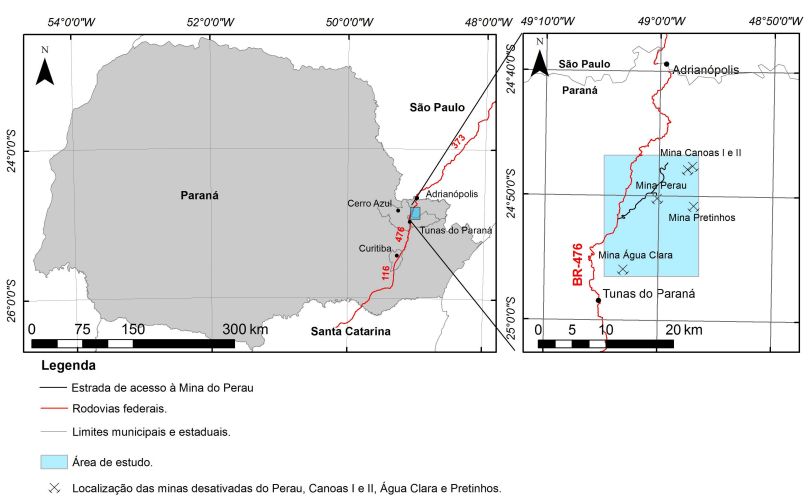

Figura 1 - Mapa de localização da área de estudo.

A região estudada compreende rochas paleoproterozoicas do Núcleo Tigre, rochas mesoproterozoicas das formações Perau e Votuverava, granitos neoproterozoicos e rochas básicas e alcalinas do Mesozoico (Fig. 2). O Núcleo Tigre é composto de sieno e monzogranitos miloníticos com idade de 1,75 Ga (Cury et al., 2002), em contato com quartzitos da base da Formação Perau. A Formação Perau apresenta coluna estratigráfica definida por Daitx (1996), onde na Sequência basal ocorrem predominantemente quartzitos, na intermediária prevalecem rochas calciossilicáticas e mármores, e na superior filitos, xistos e rochas metabásicas intercaladas, estas com idade de 1,45 Ga (Siga Junior, 2011). Os depósitos de $\mathrm{Pb}-\mathrm{Zn}$-Cu das minas do Perau, Canoas e Água Clara ocorrem hospedados em rochas calciossilicáticas na Sequência intermediária da Formação Perau. A Zona de Cisalhamento Ribeirão Grande define parte do contato entre as formações Votuverava e Perau. A Suíte Granítica Varginha, intrudida em rochas da Formação Votuverava, é formada por sieno e monzogranitos com idade de $600 \mathrm{Ma}$ (Basei et al, 2003). Por fim, ocorrem intrusões ígneas básicas, de direção geral N45W, relacionadas aos enxames de diques básicos do Mesozoico. 


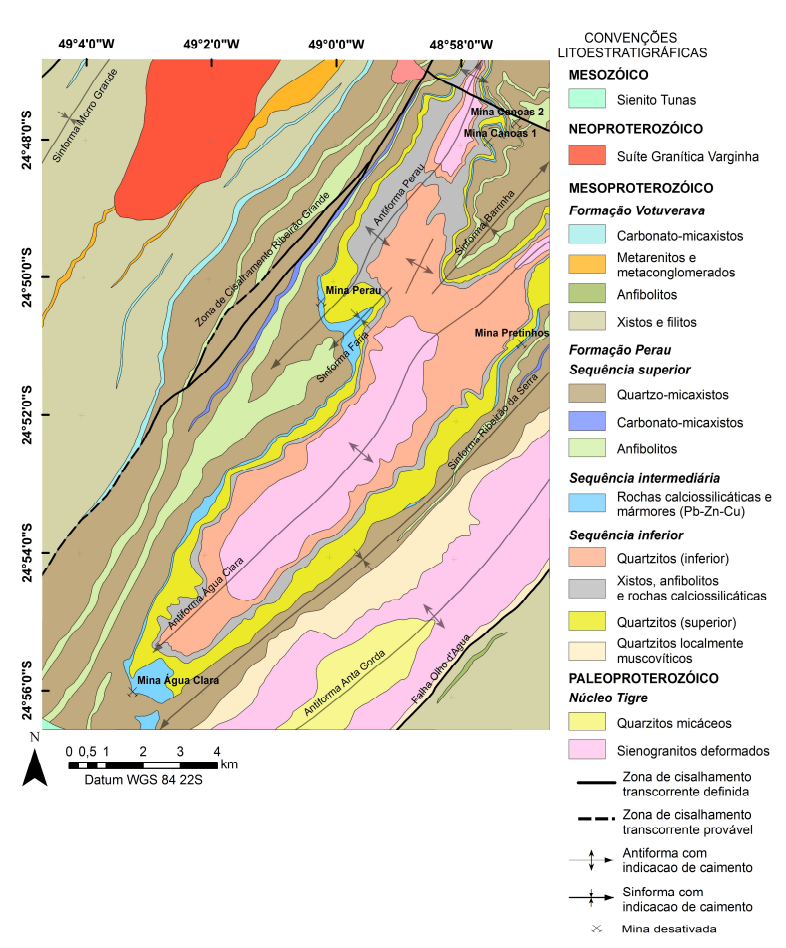

Figura 2 - Mapa geológico simplificado da área de estudo. Modificado de Daitx (1996).

\section{Métodos}

Os dados litológicos e estruturais foram resgatados do mapa geológico, em escala 1:25.000, de Daitx (1996), por meio de técnicas de geoprocessamento em ambiente SIG.

Os dados aerogeofísicos, gamaespectrométricos e magnetométricos, foram levantados com linhas de voo espaçadas de $500 \mathrm{~m}$, segundo a direção N-S. As linhas de controle, perpendiculares, foram separadas de $10 \mathrm{~km}$. A altura de nominal de voo foi de $100 \mathrm{~m}$. Para o processamento e interpretação dos dados geofísicos foram utilizados os software Oasis Montaj ${ }^{\mathrm{TM}}$ e ArcGis $^{\mathrm{TM}}$, respectivamente.

Para a confecção do mapa litogeofísico foram gerados mapas do $\mathrm{K}$, do eTh, do eU e ternário RGB. O mapa litogeofísico exibe domínios gamaespectrométricos interpretados com base nos teores relativos dos três radioelementos. $O$ resultado foi posteriormente validado pelos dados geológicos (Fig. 6).

Para a análise magnetométrica foram utilizados os dados do campo magnético anômalo reduzidos ao polo, com continuação para cima de 100 metros. Sobre este foram aplicados vários métodos de realce como Inclinação do Sinal Analítico (ISA) de Miller \& Singh (1994), Inclinação do Sinal Analítico do Gradiente Horizontal Total (ISAGHT), de Ferreira et al. $(2010,2013)$ e Signum transform de segunda ordem (de Souza \& Ferreira 2012). A interpretação qualitativa resultou num mapa de lineamentos magnéticos, o qual foi posteriormente cotejado aos dados geológicos.

\section{Resultados}

\section{Gamaespectrometria}

A Figura 3 mostra os mapas do potássio $(\mathrm{K}, \%)$, do tório (eTh, ppm), do urânio (eU, ppm) e ternário (RGB), com sobreposição dos domínios gamaespectrométricos. Tais domínios foram delineados com base nos teores relativos de K, eTh e eU (Fig. 4), os quais serão descritos a seguir em correspondência ao mapa geológico da Figura 2.
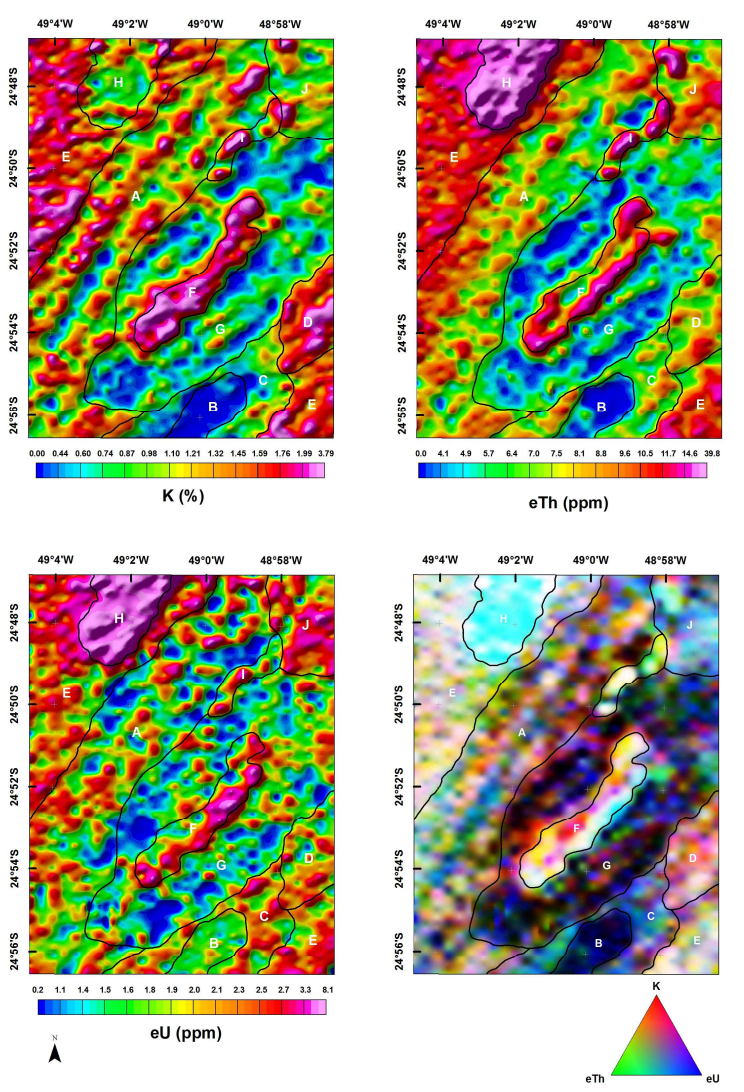

Figura 3 - Mapas radiométricos. A) Potássio (K), B) Tório (eTh), C) Urânio (eU) e D) Ternário (RGB), indicando os domínios gamaespectrométricos ( $A$ a J) (Fedalto, 2015).

O domínio A é constituído por filitos e xistos da Formação Votuverava, em contato com xistos, filitos e anfibolitos intercalados da Sequência superior da Formação Perau, sendo o posicionamento do contato entre as duas formações aproximado, devido à similaridade litológica.

O domínio B é composto por quartzitos micáceos sobrepostos ao Núcleo Tigre. Os limites deste domínio guardam boa correspondência com o contato geológico dos quartzitos, reflexo do contraste composicional com as rochas sienograníticas do domínio C e D.

O domínio E ocorre em dois tratos, um a Noroeste e outro a Sudeste, os quais pertencem a Formação Votuverava e estão separados pela Formação Perau. Tais segmentos são compostos, em sua maioria, por 
filitos e xistos com intercalações subordinadas de anfibolitos.

O domínio $\mathrm{F}$ representa exposição do Núcleo Tigre na porção central da área de estudo, o qual é composto essencialmente por sienogranitos e monzogranitos deformados.

O domínio $\mathrm{G}$ é caracterizado por baixos teores de $\mathrm{K}$, eTh e eU, reflexo direto da composição litológica. Neste domínio afloram predominantemente quartzitos da Sequência inferior, rochas calciossilcáticas e mármores da Sequência intermediária e, subordinadamente, anfibolitos e xistos da Sequência superior da Formação Perau. Este domínio compreende as minas do Perau, Canoas e Água Clara.

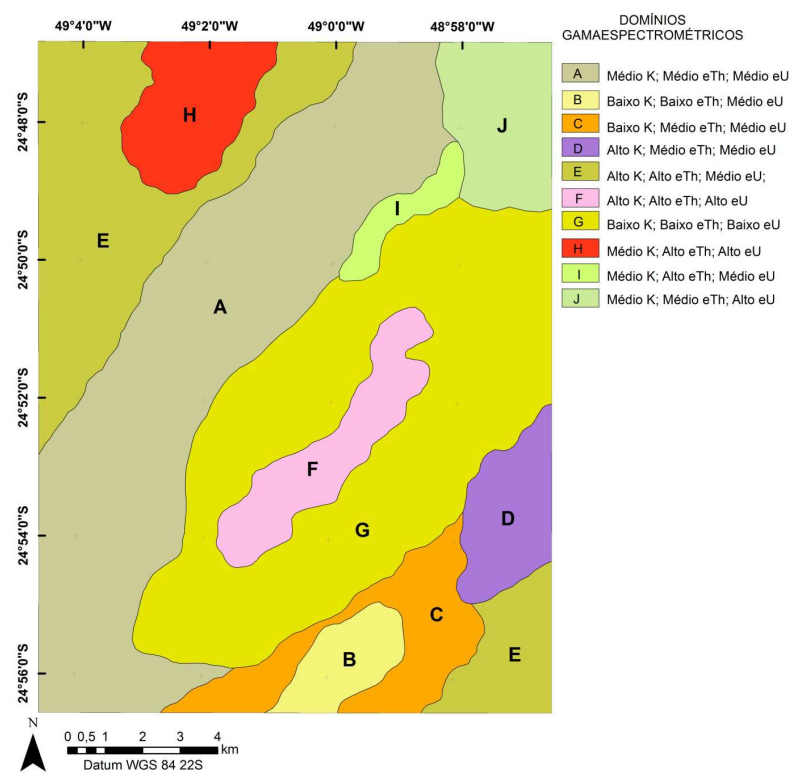

Figura 4 - Mapa litogeofísico com os domínios gamaespectrométricos (Fedalto, 2015).

O domínio H reflete a Suíte Granítica Varginha, composta por sienogranitos, monzogranitos e quartzossienitos. Gamaespectrometricamente é bem delineado por altos teores de eTh e eU.

O domínio I é formado por quartzitos, biotita-anfibólio xistos e, localmente, rochas calciossilicáticas e carbonáticas da Formação Perau. Contudo, diferentemente do domínio $\mathrm{G}$, que apresenta composição litológica semelhante, sua resposta gamaespectrométrica se assemelha à do domínio $\mathrm{F}$, o qual, por sua vez, é constituído majoritariamente por sienogranitos.

O domínio J é composto por sienogranitos do Núcleo Tigre, quartzo-micaxistos e anfibolitos da Sequência superior e, subordinadamente, quartzitos e rochas calciossilicáticas das sequências inferior e intermediária da Formação Perau. Sua resposta gamaespectrométrica aparenta refletir a predominância de sienogranitos e quartzo-micaxistos. Este domínio compreende a região da mina de Canoas.

\section{Magnetometria}

Com base no mapa do campo magnético anômalo foram delineados vários domínios (Fig. 5a), cujas amplitudes foram agrupadas da seguinte forma: (i) muito baixas (A e $\mathrm{K})$; (ii) baixas (B, D e M); (iii) intermediárias ( $\mathrm{F}$ e J) e (iv) altas (C, E, G, H, I, L e N). A interpretação conjunta dos mapas da Figura 5 permitiu delinear três tendências principais de lineamentos magnéticos: (i) N30-45E, que se reflete nos domínios magnéticos com maiores amplitudes (C, G, H e L, Fig. 5a); (ii) N30W, que na porção Nordeste da área apresenta elevadas amplitudes (Domínio I, Fig. 5a); e (iii) lineamentos flexionados a partir da direção geral Nordeste (e.g. limite meridional do domínio H).
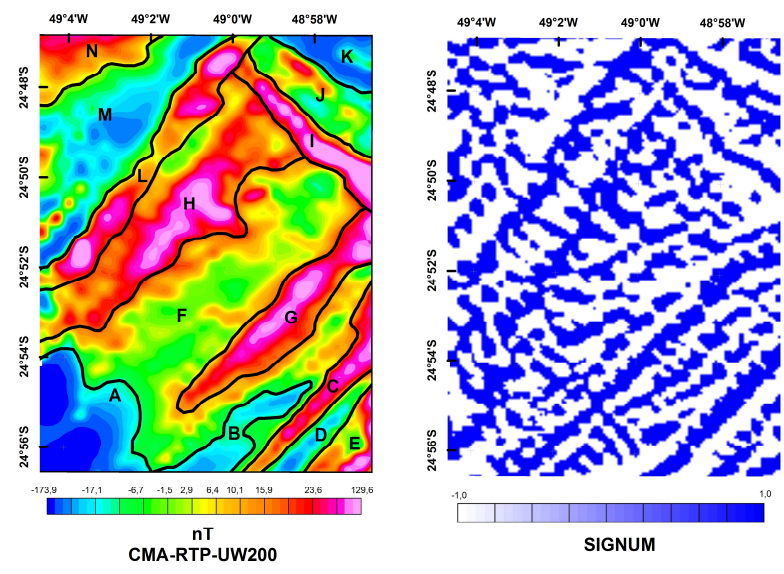

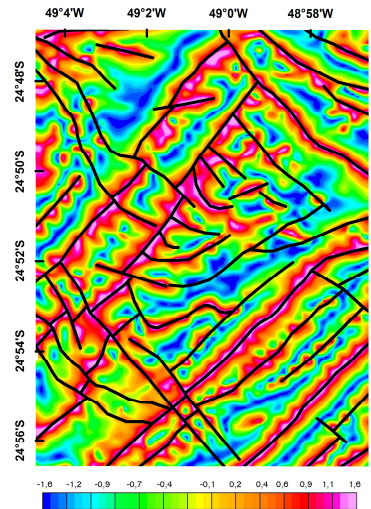

rad
ISA

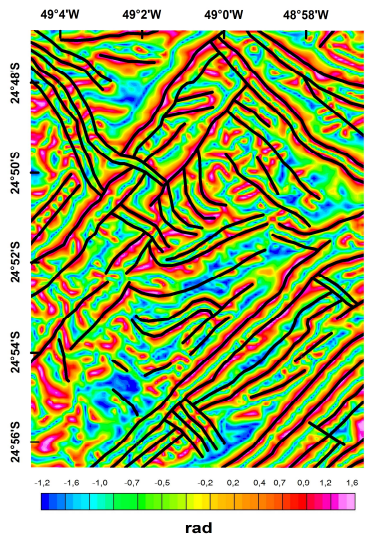

$\underset{\text { ISA-GHT }}{\mathrm{rad}}$
Figura 5 - Mapa magnetométricos: A) Campo Magnético Anômalo (CMA-RTP); B) Signum Transform; C) Inclinação do Sinal Analítico (ISA); D) Inclinação do Sinal Analítico do Gradiente Horizontal Total (ISA-GHT) (Fedalto, 2015).

Os lineamentos de direção N30-45E foram interpretados principalmente como zonas de cisalhamento (ZC), assim nomeadas, de Noroeste para Sudeste: ZC Maria Rita, ZC Ribeirão Grande, ZC Água Clara, ZC Anta Gorda e ZC Olho d’Água (em preto na Fig. 7). 
Os lineamentos de direção N30W (em vermelho na Fig. 7) são posteriores às zonas de cisalhamento, pois as seccionam com cinemática predominantemente sinistral.

Lineamentos flexionados na porção central da área foram correlacionados à rochas metabásicas, com eixos de direção N30-45E.

\section{Discussão e Conclusões}

A análise dos dados radiométricos permitiu identificar as principais unidades geológicas da área de estudo, como - Núcleo Tigre, a Formação Perau, a Formação Votuverava e a Suíte Granítica Varginha. Dessa forma, as assinaturas gamaespectrométricas de cada domínio se mostraram correlacionáveis com o mapa geológico. A distinção de domínios litogeofísicos foi possibilitada pelo contraste composicional dos litotipos, por exemplo, corpos sienograníticos em contato com quartzitos e calciossilicáticas da Sequência inferior da Formação Perau.

Os lineamentos magnéticos confirmaram zonas de cisalhamento já cartografadas na região (Daitx, 1996), como as de Ribeirão Grande e Olho d'Água, além de sugerir outras como as de Maria Rita, Água Clara e Anta Gorda. A sobreposição de zonas de cisalhamento aos limites dos domínios gamaespectrometricos sugere controle tectono-estratigráfico entre as Formações Votuvera, Perau e o Núcleo Tigre. Contudo, a confirmação destas interpretações necessita de trabalhos de campo.

Os lineamentos de direção preferencial N30W são mais recentes que as zonas de cisalhamento. Estes lineamentos são correlacionáveis a falhas/fraturas extensionais preenchidas por diques de diabásio datados do Mesozoico. Daitx (1996) salienta a importância destas estruturas na direção NW que deslocam o minério das minas de Canoas I e II.

Os lineamentos magnéticos observados no centro da área de estudo, próximo a Mina do Perau, foram interpretados como rochas metabásicas dobradas com eixo correspondente a Antiforma Perau. Os lineamentos magnéticos que refletem os corpos metabásicos formam possíveis dobras de arrasto truncadas pela Zona de Cisalhamento Ribeirão Grande, possivelmente de caráter deformacional dúctil a dúctil-rúptil.

\section{Agradecimentos}

Os autores agradecem à CPRM (Serviço Geológico do Brasil) pela cessão dos dados aerogeofísicos. F.J.F. Ferreira agradece ao CNPq pela Bolsa de Produtividade em Pesquisa (contrato 306978/2015-6).

\section{Referências}

Basei, M.A.S.; Siga JR., O.; Kaulfuss, G. A.; Cordeiro,H.; Nutman, A.; Sato, K.; Cury, L. F.; Prazeres Filho, H. J.; Passarelli, C. R.; Harara, O. M.M.; Reis Neto, J. M. 2003.
Geochronology and isotope geology of Votuverava and Perau mesoproterozoic basins, Southern Ribeira Belt, Brazil. In: IV South American Symposium on Isotope Geology - SSAGI, 4. Anais... Salvador: v. 2, p. 501-504.

CPRM - Serviço Geológico do Brasil. 2011. Projeto Aerogeofísico Paraná-Santa Catarina. Relatório final do levantamento e processamento dos dados magnetométricos e gamaespectrométricos. Texto Técnico. Volume I, 87p.

Cury, L.F; Kaulfuss, G. A; Siga JR., O; Basei, M.A.S; Harara, O. M.M; Sato, K. 2002. Idades U-Pb (zircões) de $1.75 \mathrm{Ga}$ em granitoides alcalinos deformados dos núcleos Betara e Tigre: evidências de regimes extensionais do Estateriano na Faixa Apiaí. Geol. USP, Sér. cient., São Paulo, v. 2, p. 95-108.

Daitx, E.C. 1996. Origem e evolução dos depósitos sulfetados tipo Perau ( $\mathrm{Pb}-\mathrm{Zn}-\mathrm{Ag}$ ), se nas jazidas Canoas e Perau (Vale do Ribeira, PR). Tese (Doutorado) Instituto de Geociências e Ciências Exatas, Universidade Estadual Paulista Júlio de Mesquita, Rio Claro.

Fedalto, G. 2015. Integração de dados geológicos e aerogeofísicos da região da Mina do Perau, Vale do Ribeira, Paraná. Trabalho de Conclusão de Curso, Departamento de Geologia, Universidade Federal do Paraná, 63 p.

Ferreira, F. J. F., Souza, J., Bongiolo, A. B. S., Castro, L. G., Romeiro, M. A. T. 2010. Realce do gradiente horizontal total de anomalias magnéticas usando a inclinação do sinal analítico. Parte I: Aplicação a dados sintéticos. IV Simpósio Brasileiro de Geofísica, 1, 1-6. Brasília: SBGf.

Ferreira, F. J. F., Souza, J., Bongiolo, A. B. S, Castro, L. G. 2013. Enhancement of the total horizontal gradient of magnetic anomalies using the tilt angle. Geophysics, 78(3), J33-J41.

Miller H.G. \& Singh V. 1994. Potential field tilt - a new concept for location of potential field sources. Journal of Applied Geophysics. 32: 213-217.

Siga Júnior, O.; Basei, M.A.S., Sato, K., Passarelli, C.R., Nutman, A., Mcreath, I., Prazeres Filho, H.J. 2011. Calymmian (1.50-1.45 Ga) magmatic records in Votuverava and Perau sequences south-southeastern Brazil: zircon ages and $\mathrm{Nd}-\mathrm{Sr}$ isotopicgeochemistry. J. South Am. Earth Sci. 32, 301-308.

de Souza, J., and F. J. F. Ferreira, 2012, On the use of derivatives for interpreting magnetic anomalies due to dykelike bodies: Qualitative and quantitative analysis. Istanbul 2012 - International Geophysical Conference and Oil \& Gas Exhibition, SEG. 


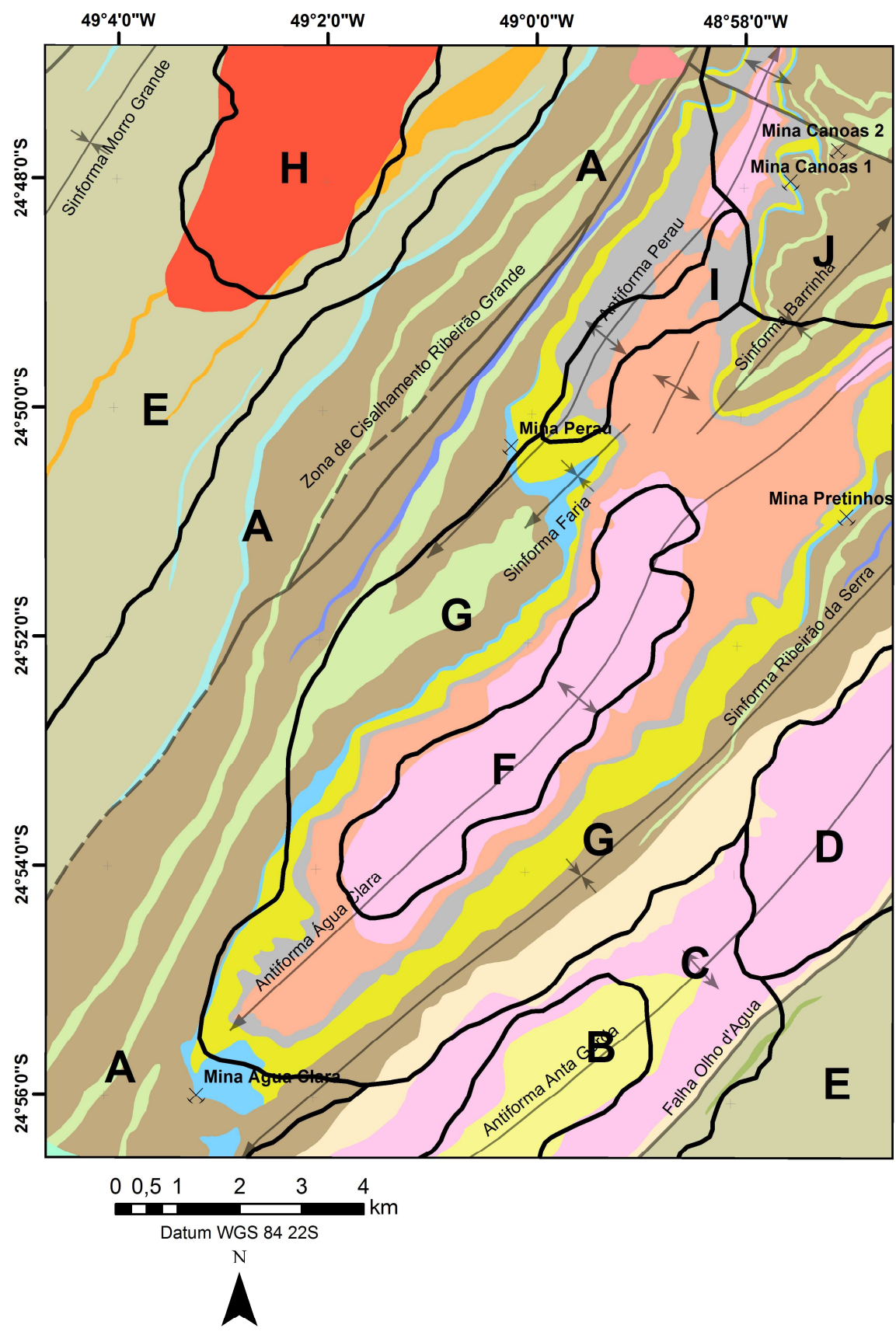

CONVENCÕES

LITOESTRATIGRÁFICAS

MESOZÓICO

Sienito Tunas

\section{NEOPROTEROZÓICO}

Suíte Granítica Varginha

\section{MESOPROTEROZÓICO}

Formação Votuverava

$\square$ Carbonato-mica xistos

Metarenitos e

metaconglomerados

Anfibolitos

Xistos e filitos

\section{Formação Perau}

Sequência superior

Quartzo-mica xistos

Carbonato-mica xistos

Anfibolitos

\section{Sequência intermediária}

Rochas calciossilicáticas e mármores (Pb-Zn-Cu)

\section{Sequência inferior}

Quartzitos (inferior)

Xistos, anfibolitos

e rochas calciossilicáticas

Quartzitos (superior)

Quartzitos localmente muscovíticos

PALEOPROTEROZÓICO

Núcleo Tigre

Quarzitos micáceos

Sienogranitos deformados

Zona de cisalhamento

transcorrente definida

- - Zona de cisalhamento transcorrente provável

$\uparrow$ Antiforma com

indicacao de caimento

$\stackrel{\text { Sinforma com }}{\longrightarrow}$

indicacao de caimento

× Mina desativada

Figura 6 - Mapa geológico (modificado de Daitx, 1996) indicando os domínios gamaespectrométricos apresentados na figura 4. Fonte: Fedalto (2015). 

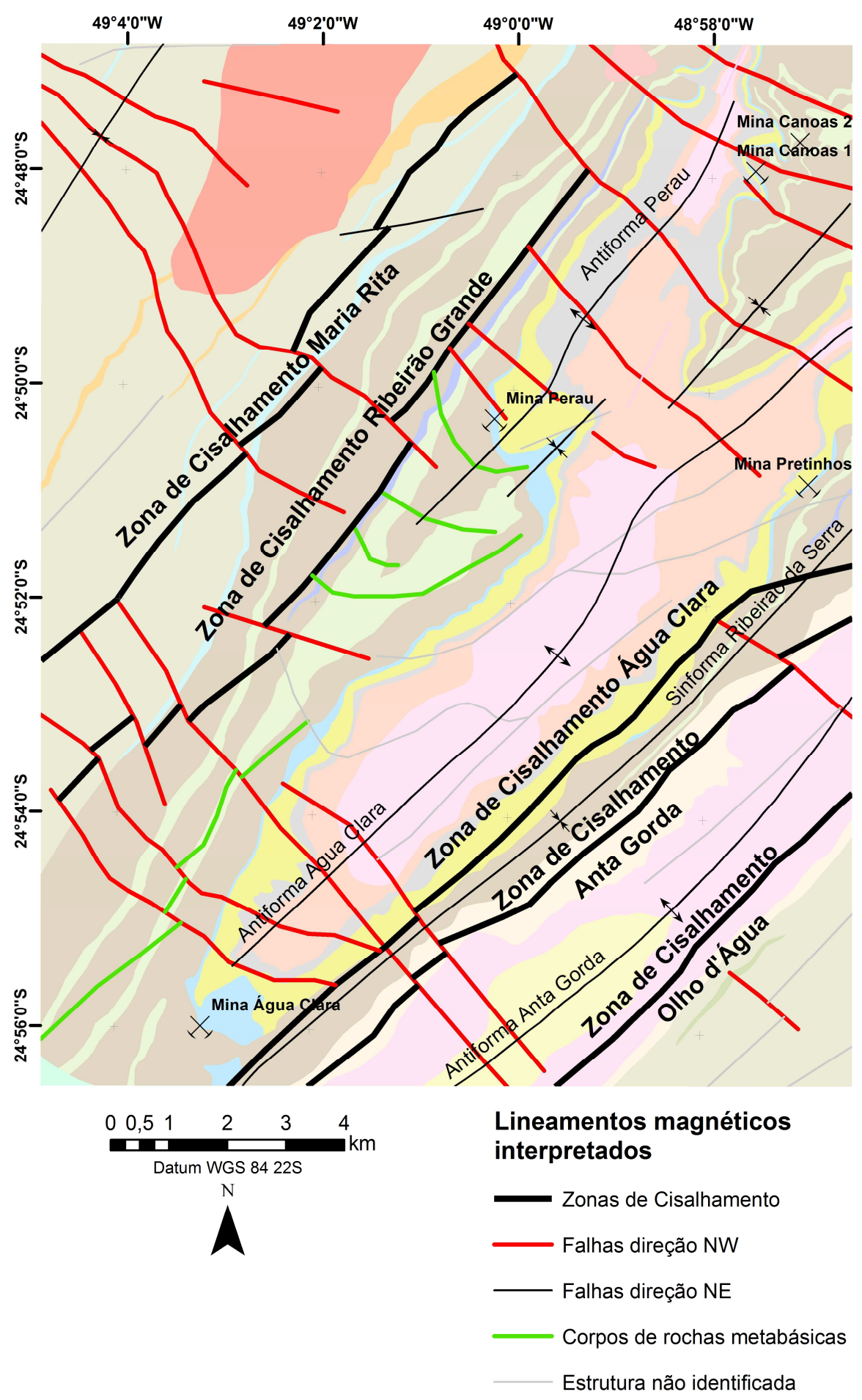

CONVENÇÕES

LITOESTRATIGRÁFICAS

MESOZÓICO

Sienito Tunas

\section{NEOPROTEROZÓICO}

Suíte Granítica Varginha

\section{MESOPROTEROZÓICO}

Formação Votuverava

\begin{tabular}{|c|c|}
\hline & Carbonato-mica xistos \\
\hline & $\begin{array}{l}\text { Metarenitos e } \\
\text { metaconglomerados }\end{array}$ \\
\hline & Anfibolitos \\
\hline & Xistos e filitos \\
\hline $\begin{array}{l}\text { Forma } \\
\text { Sequêt }\end{array}$ & $\begin{array}{l}\text { ção Perau } \\
\text { cia superior }\end{array}$ \\
\hline & Quartzo-mica xistos \\
\hline & Carbonato-mica xistos \\
\hline & Anfibolitos \\
\hline
\end{tabular}

Sequência intermediária

Rochas calciossilicáticas e mármores (Pb-Zn-Cu)

\section{Sequência inferior}

Quartzitos (inferior)

Xistos, anfibolitos e rochas calciossilicáticas

Quartzitos (superior) Quartzitos localmente muscovíticos

\section{PALEOPROTEROZÓICO}

Núcleo Tigre

Quarzitos micáceos Sienogranitos deformados Zona de cisalhamento transcorrente definida

- Z - Zona de cisalhamento transcorrente provável

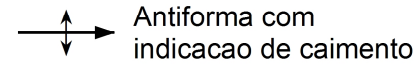

$\stackrel{\text { Sinforma com }}{\longrightarrow}$

$x \quad$ Mina desativada

Figura 7- Mapa geológico (modificado de Daitx, 1996) indicando os lineamentos magnéticos interpretados. Fonte: Fedalto (2015). 